\title{
Language Proficiency Level and Intake of Nominal Group Use in Scientific English: A Web Classroom Empirical Study
}

\author{
Pilar Durán ${ }^{1} \&$ Ana Luz Rubio ${ }^{2}$ \\ ${ }^{1}$ Mining Engineering School, Universidad Politécnica de Madrid, Spain \\ ${ }^{2}$ Industrial Engineering School, Universidad Politécnica de Madrid, Spain \\ Correspondence: Pilar Durán, Mining Engineering School, Universidad Politécnica de Madrid, Spain. E-mail: \\ pilar.duran@upm.es
}

$\begin{array}{ll}\text { Received: January 22, } 2015 & \text { Accepted: February 12, } 2015 \quad \text { Online Published: March 29, } 2015 \\ \text { doi:10.5539/ijel.v5n2p8 } & \text { URL: http://dx.doi.org/10.5539/ijel.v5n2p8 }\end{array}$

\begin{abstract}
Focusing on the teaching-learning of nominal group use in science and technology through input noticing, this article deals with a pedagogical application of technological resources to the acquisition of grammar competence in English by a group of 50 senior year Spanish engineering students with different CEFR English level, ranging from $\mathrm{A} 2$ to $\mathrm{C} 1$. Students received training to notice nominal groups in an input of specialized engineering articles in the Web classroom, as part of the core subject English for Academic and Professional Communication syllabus, taught at the Technical University of Madrid (Spain). The results of the statistical analysis revealed that the entire group improved their ability to use noun compounds correctly, and that the students' CEFR level affects the student's initial and final marks, but not their improvement in nominal group use. It was concluded that this approach, which integrated technology-enhanced noticing into the course methodology, improved the students' performance and, therefore, can be profitably implemented for the acquisition of grammar competence.
\end{abstract}

Keywords: input noticing, nominal groups, scientific English, technology-enhanced noticing

\section{Introduction}

The scarce grammar instruction in the Communicative Approach to English for Science and Technology (EST) teaching has often produced students who communicate well but lack grammatical competency. Academic and professional communication demands correctness, but how is it possible to teach grammar in a way that will help students develop grammatical competency with a communicative approach? This article discusses a possible answer to this question: the theory of noticing and its implementation through technology-enhanced language intake. Previous data confirm that students who have explicit grammar instruction as part of their study achieve a higher level of grammatical accuracy than those who do not (Ellis, 2002, p. 19). Both Long (1988) and Ellis (1990), through reviewing a number of such empirical studies, have concluded that, overall, conscious learning seems to contribute to successful L2 development. However, there are too many linguistic rules for any learner, native speaker or not, to learn them all consciously. Therefore, the grammar features chosen for teaching-learning activities should not only be well selected on the basis of their relevance for the aims of the course and the students' language needs, but their teaching methodology updated.

\subsection{The Salience of Nominal Group Use in EST}

There are several ways of naming those long noun chains which function together as a unit and may become the subject of a verb in a sentence: noun compounds, nominal groups, nominal compounds, multiple noun compounds, etc. For the purpose of this paper, we will use 'nominal groups', as this term clearly refers to a noun phrase made up of two, three or more nouns functioning together as a unit, $v s$ 'noun compounds' which is often used (though not exclusively) to refer to two-word expressions such as 'telephone box', 'switch board' or 'personal computer', whose meaning cannot be expressed in a single word.

Nominal groups (NGs) occur in EST much more frequently than in any other field. Salager-Meyer (1984, pp. 15-146) carried out a study to compare the occurrence of long NGs in general and technical English texts. Using two similar corpora in length and quality of language, the author found out that long NGs in general English appeared $0.87 \%$, whereas in technical English it occurred $12.37 \%$. Furthermore, focusing on long NGs of more than four elements, she found out that NGs were used 20 times more frequently in technical English. Likewise, 
Biber, Conrad and Reppen (1998, p. 579) corpus linguistics study found out that "proportionally, in academic prose, almost $60 \%$ of all noun phrases have some modifier, of which $25 \%$ have a premodifier and $20 \%$ have a postmodifier". Premodifiers studied went up to four tokens. Soto, Martínez and Sadowsky's (2006) study on the use of nouns $v s$ verbs by academics of different fields concluded that the relationship noun/verb in the case of applied sciences and earth sciences was $75 / 25$ and 70/30, respectively; whereas in the case of academics from human and social sciences it was 60/40 in both cases.

Referring to "writing science", Halliday and Martin affirm that even a native speaker of English may be familiar with the science concepts but not know how to express them in English:

"The difficulty lies more with the grammar than with the vocabulary... Technical terms are not in themselves difficult to master. The problems with technical terminology usually arise not from the technical terms themselves but from the complex relationships they have with one another" (Halliday \& Martin, 1993, p. 71).

Furthermore, in a study dealing with the evaluation of competent use of EST features by Spanish L1 engineering students, Durán and Rubio (2015) found out that the correct use of NGs is by far the most difficult EST feature to acquire. There are three main reasons why Spanish L1 scientists find it so difficult to use NGs when writing in English:

a) Compounding is not a natural language process in Spanish, as it is in English. NGs structure (modifier1 + modifier $2+$ modifier $3 \ldots+$ head noun) does not exist as such. In Spanish, prepositional phrases or relative clauses are used instead (Bocanegra, 2007, p. 75).

b) Word order. Nouns are arranged in different order for each language. In Spanish, modifiers come after the head noun (gas que causa una reacción química), while in English modifiers come before it (chemical reaction gas).

c) The complexity of the semantic interpretation of long NGs, which can be highly context dependent, or because there can be more than one semantic relation encapsulated in a pair of nouns (Trimble, 1985, p. 131; Girju, Moldovan, Tatu, \& Antohe, 2005, pp. 479-480). An example of a context dependent interpretation is 'GM car', where one has to know that GM is a car-producing company. Another example to illustrate the case of more than one possible semantic interpretation of the noun phrase is 'technology research programme', which could be interpreted as a 'programme for research in technology' or as a 'research programme using technology'. Again, the context where the term has been used will clarify its meaning. This is why, presenting real input language is so important, rather than teaching NGs formation isolated from context.

\subsection{Training Learners to Notice Linguistic Forms}

Conscious learning is the crucial concept of noticing (Skehan, 1998, p. 48). Noticing focuses on concrete features of real language use and, therefore, it may be considered as an effective source of available information for competent L2 learners. Noticing is basically the result of the learner's paying attention to the form and meaning of certain language structures in a given input. According to Schmidt (1995, p. 20), "the noticing hypothesis states that what learners notice in input is what becomes intake for learning." Schmidt also states that whether a learner deliberately attends to a linguistic form in the input or it is noticed purely unintentionally, if it is noticed it becomes intake. The author adds that noticing is a necessary (though not sufficient) condition for L2 acquisition

Noticing involves 'noticing the gap', i.e. identifying how the input to which the learner is exposed to differs from the output the learner is able to produce at a given learning stage. In the case of NG, the gap is evident, especially in the first stages of English L2 learning, as this structure does not occur in Spanish in the same way. Thus, a Spanish L1 engineering student would tend to say 'activities for processing information' rather than 'processing information activities' before intaking the NG language structure. Therefore, noticing involves the learner's recognition that the L2 features noticed are different from those in their L1 and, hopefully, this awareness will aid learners notice target forms in subsequent input and help the eventual acquisition of these forms (Ellis, 2002, p. 29).

Intake, a term first coined by Corder (1967), refers to those language features the learner successfully processes to build up internal understanding of $\mathrm{L} 2$ :

The simple fact of presenting a certain linguistic form to a learner in the classroom does not necessarily qualify it for the status of input, for the reason that input is "what goes in" not what is available for going in, and we may reasonably suppose that it is the learner who controls this input, or more properly his intake (Corder, 1967, p. $165)$. 
We cannot expect our learners all to be at the same stage in their English L2 learning. Pienemann (Pienemann \& Johnson, 1987; Spada \& Lightbow, 1999) explained the concept of 'learnability' suggesting that learners at any one stage will find 'learnable' only those language items that are at just the next stage of their natural acquisition. The author adds that it may be possible to accelerate the learners' progress, but not to jump stages altogether. Their intake capacity must be supported by other previous knowledge so that input and intake may become parts of the same learning process (Van Patten, 2002). In heterogeneous classes as ours, having students with A2 to C1 English level -according to the Common European Framework of Reference (Note 1) (CEFR) for language competence levels-, the concept of learnability needs to be present in programming class activities; however, certain complex structures should not be left aside as the majority of students benefit from being exposed to them, though in different degrees, as we shall see in this study.

According to Ellis (2002), the stage in which input becomes intake involves learners noticing language features in the input, absorbing them into their short-term memories and comparing them to features produced as output. Cross (2002), following Schmidt (1990), claims that four factors facilitate learners drawing attention to certain features in input:

- $\quad$ Explicit instruction: explaining and drawing attention to a particular form, which ensures understanding the grammar point. With help from the teacher, the students analyse the data and "discover" the rule.

- $\quad$ Frequency: the regular occurrence of a certain structure in input; the more frequent an item, the greater number of opportunities for noticing.

- Perceptual Salience: highlighting or underlining to draw attention to a certain structure to make it prominent in input.

- $\quad$ Task Demands: constructing a task that requires learners to notice a structure in order to complete it.

In relation to explicit instruction, Ellis (2002) warns that this is not designed to develop implicit knowledge, but simply to develop awareness of grammar, which-when supplemented with other forms of input and communicative tasks - may aid in the eventual acquisition of implicit knowledge.

\section{Methodology of the Study}

As we have seen above, NGs compounding requires both frequent exposure to real scientific texts input, and subsequent conscious reflection on the part of the students. Explicit instruction will ensure understanding of this particular language structure characteristic of EST. Furthermore, using the web classroom for this purpose is considered to be a useful teaching-learning means of facilitating learners to keep their own pace when intaking NGs use. The Web classroom allows students an easy access to materials explaining the new structure and related exercises, and helps teachers develop and collect assignments paperlessly providing direct, time-saving feedback. External links to grammar references to reinforce the presence of NGs in EST were also provided by the teacher.

The platform includes password identification and four modules: subject information database, communication tools, practical exercises, and self-assessment. This way, students can keep track of what is being done and review both theory and practical applications whenever they need it. The possibility of having this open access to class content enhances communication among student participants as well.

Therefore, in order to consider our pedagogical application as valid, the following questions need to be answered:

- Are all students above A2 level, regardless of their previous language proficiency, capable of intaking the NGs structure?

- What is the minimum CEFR language level above A2 (Council of Europe, 2001) required to intake NGs and use them efficiently?

- Is web Classroom guided exposure to a large amount of scientific texts a sufficient means to ensure training learners to notice and intake NGs?

The steps followed in our proposal to train learners to notice and intake NGs are as follows:

a) Formal instruction as a way to raise consciousness of NGs presence in specialized electrical and electronic engineering publications. This will provide explicit grammar knowledge of what NGs are and how and why they are used in the students' specific contexts.

b) Input selection of relevant scientific articles, which are then uploaded in the Web classroom. 
c) Noticing activities: underlining and classifying NGs present in the articles followed by 'noticing the gap'. Students are asked to introduce their personal work in the online classroom application so that they, individually and in groups, may go back to reflect on their answers.

d) Intake of the new feature processed, so as to be able to use it in ad hoc tasks also found in the web class.

e) Evaluating intake by means of direct and inverse translation exercises.

\subsection{The Participants}

The study involved a group of senior year industrial engineering students, majoring in Electrical engineering, enrolled in the subject English for Academic and Professional Communication taught at the Technical University of Madrid. Enrolment in the subject did not require a minimum English level, other than having passed the University entering exam which requires a B1 foreign language level. The final sample included 50 students who participated voluntarily, assisted to class regularly and fulfilled all the requirements of the study.

In order to find out their CEFR English level (Council of Europe, 2001), the participants were required to take the Oxford Placement Test (Note 2) the first day of class. Results show: 7 A2+, 21 B1, 14 B2 and 8 C1 English level students. This wide range allowed us to take language proficiency into account as a variable in NG use intake. The senior year Industrial Engineering students involved in the study were used to the Web classroom, since almost $80 \%$ of their subjects use it regularly. Its interface design is easy to use and has been running in the Industrial Engineering School for more than 15 years successfully.

\subsection{The Texts Used}

The following ten articles (from 7.000 to 10.000 words) were chosen to construct the tasks requiring noticing of NG use in EST communication (Note 3):

- “A compact tree-phase single-input/dual-output matrix converter”. X. Liu, P. Wang, Ch. Loh, \& F. Blaabjerb. (IEEE Transactions on Industrial Electronics, Vol. 59. No 1, January 2012).

- "An Advanced Power Electronics Interface for Electric Vehicles Applications". Omar Hegazy, Ricardo Barrero, Joeri Van Mierlo, Philippe Lataire, Noshin Omar, \& Thierry Coosemans. (IEEE Transactions on Power Electronics, Vol. 28, No. 12, December 2013).

- "Overview of Control and Grid Synchronization for Distributed Power Generation Systems". Frede Blaabjerg, Remus Teodorescu, Marco Liserre \& Adrian V. Timbus. (IEEE Transactions on Industrial Electronics, Vol. 53, No. 5, October 2006).

- "Analyzing image deblurring through three paradigms". Ch. Wang, L.Sun, P.Cui, J.Zhang, \& S. Yang. (IEEE Transactions on Image Processing, Vol. 21, No. 1, January 2012).

- "Image quality assessment: from error visibility to structural similarity". Z. Wang, A.C. Bovik, H.R. Sheik, \& E.P. Simoncelli. (IEEE Transactions on Image Processing, Vol. 13, No. 4, April 2013).

- "Automatic segmentation of colour images with transitive closure". M.O. Incetas, R. Demirci, \& H.G. Yavuzcan. (IEEE Transactions on Image Processing, Vol. 13, No. 5, September 2013).

- "Datasheet Driven Silicon Carbide Power MOSFET Model". Mihir Mudholkar, Shamim Ahmed, M. Nance Ericson, S. Shane Frank, Charles L. Britton, Jr. \& H. Alan Mantooth. (IEEE Transactions on Power Electronics, Vol. 29, No. 5, May 2014).

- "Performance Improvement by Stress Memorization Technique in Trigate Silicon Nanowire MOSFETs". Masumi Saitoh, Yukio Nakabayashi, Kensuke Ota, Ken Uchida, \& Toshinori Numata. (IEEE Electron Device Letters, Vol. 33, No. 1, January 2012).

- "Matching Pursuits with Time-Frequency Dictionaries". StCphane G. Mallat \& Zhifeng Zhang. (IEEE Transactions on Signal Processing Vol. 41, No. 12, December 1993).

- “Cognitive Radio: Brain-Empowered Wireless Communication”. Simon Haykin (IEEE Journal On Selected Areas In Communications, Vol. 23, No. 2, February 2005).

\subsection{The Tests Employed to Evaluate Intake}

Students went through two translation tests -English/Spanish and Spanish/English- before and after receiving training to notice NGs in input. They were designed by Rubio Moreda (2015) for the study. We used translation because it offers a valuable tool to test the acquisition of concrete linguistic competencies (Titford, 1983). Likewise, Newmark (1992, p. 61) affirms that "translation may be useful as a form of control and consolidation of grammar and vocabulary, and in dealing with errors". The same tests were administered to the entire group 
before and after treatment, with an interval of six weeks between them. Students did not receive any feed-back as to their performance until the study was completed, nor were the test right answers commented on in class. The nominal phrases used were extracted from different texts whose vocabulary was familiar to engineering students. Faculty members from the Industrial Engineering School were consulted to determine the sources.

-The English/Spanish translation test comprised 27 items distributed as shown below, where X stands for a noun premodifier, leaving adjectives aside:

Nominal groups with 2 elements: $\quad \mathrm{X}+$ head noun 4

Nominal groups with 3 elements: $\quad \mathrm{X}+\mathrm{X}+$ head noun 10

Nominal groups with $4(5)$ elements: $\mathrm{X}+\mathrm{X}+\mathrm{X}+(\mathrm{X})+$ head noun $\quad 13$

Examples of English/Spanish translation items are:

-Mini circuits shielded frequency mixers deliver breakthrough combination (2 two-element items)

-With such a scheme products would achieve the agreed mobile networks compatibility (three-element item)

-It assists in minimizing interference automotive radar systems (four-element item)

-The equipment will help pinpoint sea level rise glacier role (five-element item).

-The Spanish/English translation test comprised other different 27 items distributed thus:

Nominal groups with 2 elements:

Nominal groups with 3 elements:

Nominal groups with 4 elements:

$$
\begin{array}{rr}
X+\text { head noun } & 5 \\
X+X+\text { head noun } & 15 \\
X+X+X+\text { head noun } & 7
\end{array}
$$

Examples of Spanish/English translation items are:

-La tecnología de los transistores sigue avanzando (two-element item)

-En el sistema de reconocimiento se utilizan herramientas de procesamiento de señales (two-element ítem, and three-element ítem)

-Las células de combustible de hidrógeno para automóviles se prueban en el laboratorio (four-element item).

As it has been shown in the examples for both direct and inverse translation, in some cases two types of NG item are found within a single sentence. Marks were given for both NGs items.

\section{Procedure}

\subsection{Formal Instruction to Raise Consciousness of NGs Presence and Their Structure}

In 1.1 we pointed out the main reasons why Spanish L1 scientists find it so difficult to use NGs. Following Trimble's work (1985, pp. 131-136 and 163-164) on lexical problems in EST discourse, to solve this difficulty learners should be trained to be aware that compounds are usually formed from prepositional and/or adverbial phrases, and/or relative clauses, and that the majority can be 'back-formed' into one or the other of these. Thus, 'laboratory equipment' is 'equipment used in a laboratory'; and 'physics laboratory' is 'a laboratory in which experiments in physics are performed'. When training non-native speakers of English to understand and use noun compounding, they should be alerted that in forming a compound from a phrase, the nouns in the phrase are put in the reverse order, considering both the use of prepositions or relative pronouns. These pieces of advice would tend to minimise the two first sources of difficulty.

The third type of difficulty EST students need to overcome is the complexity of the semantic interpretation of NGs. Long chains of nouns acting as a conceptual unit cannot be interpreted out of context; technical manuals are good examples for this. In our teaching situation, the collaboration of technical engineering course teachers has been decisive.

Attention should also be drawn to the different type of premodifiers that make up the NGs: nouns, -ed and -ing verb forms, adverbs and prepositions. Students had access to all the linguistic documentation on the matter; and also to external links to grammar references of the presence of NGs in EST provided by the professor. The information had been previously uploaded in the Web classroom platform.

\subsection{Noticing Activities Leading to Intake}

First of all, students went through the articles and chose one to carry out the exercises. Then, each student placed his/her findings in the given template so that results from the different students could be easily discussed, as more than one student selected each article. Templates had been placed online in the Web classroom. Students 
were told to leave aside adjectives qualifying nouns and numerals for the count. For instance 'a new matrix converter' should be considered as a two-element NGs. All lexical and grammatical doubts were solved in class with the entire group. All sessions lasted 90 minutes, combining lecture, personal work and group discussion of results.

In order to illustrate noticing activities, we shall present an actual example of how students worked with the first article mentioned in 2.2. The work done with the other nine articles was similar. The results we present here are the final ones, after students' individual work and group discussion, including teacher's feedback and the expert opinion of engineering staff colleagues consulted.

\subsubsection{Analysis of NGs according to number of elements}

Title: A Compact Three-Phase Single-Input/Dual-Output Matrix Converter

NGs with 2 elements: 113

matrix converter ${ }_{14}$, ac input, ac output, presented topology, proposed converter, commutation count, proposed topology, carrier requirements, modulation technique, nine-switch converter 2 , ac power, dc link ${ }_{5}$, converter reliability, matrix topologies, single-output type, traction locomotives, rear-end inverter, ac load, resulting topology, modulation indices, source network, switch

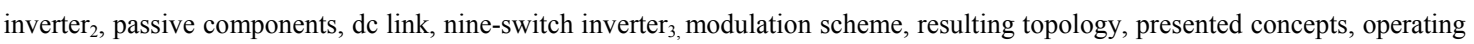
modes, modulation strategy, modulation theories ${ }_{2}$, operation principles, cascading basis, vector diagram, reference phasor, time domain, converter output, vector diagram, source voltage, modulating conditions, inverter operation, switching process, phase current, input proof, output proof, computer burden, combined effects, dc rail, clamped switch, modulated switches, carrier comparison, separation criterion, matrix modulation, rising slopes, falling slopes, modulating references ${ }_{2}$, state sequence, modulation indices, carrier peak, carrier trough, falling edge, coordination process, duty ratio, state division, modulation process, state sequences, output waveforms, synchronization process, switching losses, current values, output currents, modulation ratios, duty ratios, component parameter, implemented hardware, inductor losses, controller card, evaluation card, follow-up attempt, modulation thoughts, modulating references ${ }_{2}$, modulation indices, peak amplitudes, output current, filtered input, current peaks, output currents, amplitude relations, output voltages, impedance values, reference crossover, power flow, on switches.

\section{NGs with 3 elements: 85}

Rear-end six-switch inverter, three-phase ac outputs, carrier-based method, carrier-based modulation, speed motor drives, wind generation system, ac converter topologies, back-to-back converter ${ }_{2}$, voltage source inverters, three-phase line inductors, back-to-back topology, ac matrix converter, sparse matrix converter, ultra-sparse matrix converter ${ }_{3}$, dc link capacitor ${ }_{3}$, nine-switch proposed concept, , ac output voltages, buck-boost freedom, top-to-bottom current, existing nine-switch inverters 2 , presently unsolved shortcomings, hidden concept details, required power flow, operating possible scenarios, proposed matrix converter, source voltage phasor, assumed remaining voltages, dc-link voltage, rear-end nine-switch voltage, middle shared switches, current flow path, space vector theory, chosen space vector, sizeable lookup table, carrier based modulation, state auto sequencing, carrier based approach, space vector system, imposed line voltage, input line voltage, current reference phasor, grid voltage phasor, input voltage amplitude, normalized six-pulse variation, allowed switching states, unwanted switching states, phase shift constraint ${ }_{2}$, modulation index sum, dc-link variation ${ }_{2}$, falling edge duration, unity power factor, shown carrier diagrams, resulting state sequences, dc-link current flow, normalized modulating references, state time duration, switch duty ratio, normalized modulating voltages, obtained resulting expressions, expected regeneration capability, input filter inductance, input damping resistance, input filter capacitance, switch conduction losses, three-phase input voltages, $100 \mathrm{MHz}$ oscillator frequency, high-end control verification, observed input currents, impedance value terms, second-order input filter ${ }_{2}$, three-phase input current, per phase modulating references, input phase voltage, same amplitude output voltages, DF mode testing, modulation index sum, output line voltage, DF operation mode

NGs with 4(5) elements: 46

proposed single-input/dual-out matrix converter, unity input power factor, rear-end voltage source inverter, short-term energy storing purposes, three-phase input ac source, higher rated dc-link capacitor, bulk-rated passive components, all-semiconductor matrix conversion concept, unity power factor operation 2 , front-end current-source rectifier, front-end CSR matrix converter, resulting proposed matrix converter, passive dc-link component, associated dc-link modulation values, input current reference phasor, applied dc-link voltage $V_{d c}$, CSR input voltage waveforms, per phase-leg three switching states, matrix converter carrier based modulation, unity power factor operation, modulated switch duty ratio, varying dc-link voltage, constrained phase-leg switching states, references maximum modulation indices, varying-slope triangle carrier, CSR switching state duration, modified carrier rising edge duration, switched-controlled three-phase terminals, anticipated CSR commutation losses, yet-to-be proven remaining feature, output current power factor angles, proposed matrix converter input current, carrier-based modulation scheme, 5-kHz variable-slope triangle carrier, overall matrix converter driving signals, CF mode simulation results, per phase modified modulating references ${ }_{2}$, in-phase input phase voltage, unity input power factor ${ }_{2}$, over a half current voltage cycle, DF mode simulation results, top to bottom three-phase output currents, top to bottom filtered input currents, modulation indices imposed limits, variable-slope carrier modulation scheme 
The purpose of this first task was two-fold: to make students aware of the highly frequent presence of NGs in scientific publications of their specialty, and to notice their differences in length and frequency. The longer the NG, the less frequently it is used. We found out that this pattern was followed in the other articles studied. The subindex in some NGs shows the number of times it was found in the text.

\subsubsection{Analysis of NGs according to the Type of Premodifiers Involved}

The second task consisted of a new detailed reading of the same article, this time paying attention to the type of premodifiers involved: nouns, verbs ending in -ed or -ing, adverbs and adverbial phrases and prepositions. Adjectives qualifying nouns and numerals should not be considered. The task was introduced to the whole class so that all doubts could be solved after receiving formal instruction of the grammatical rules involved. Engineering students found greater difficulty in completing this classification; therefore a second session was needed. They were allowed to review and complete the assignment on their own or in small groups out of class. This is one of the advantages of the web classroom, as it allows students who find different degrees of difficulty to complete the task to incorporate their work without a time pressure.

The next step consisted in the teacher's checking all the exercises and providing feedback to students. The teacher got in touch with each student via e-mail whenever she considered that the student's attention needed to be drawn towards a language feature or a repeated error. This is a second advantage of web classroom work: it helps the teacher to develop and review assignments paperlessly, providing direct time saving feedback and personalized guidance to a mixed language level group of students, ranging from $\mathrm{A} 2+$ to $\mathrm{C} 1 \mathrm{CEFR}$ level in our case.

The template with the final information, as it was placed online, is shown below.

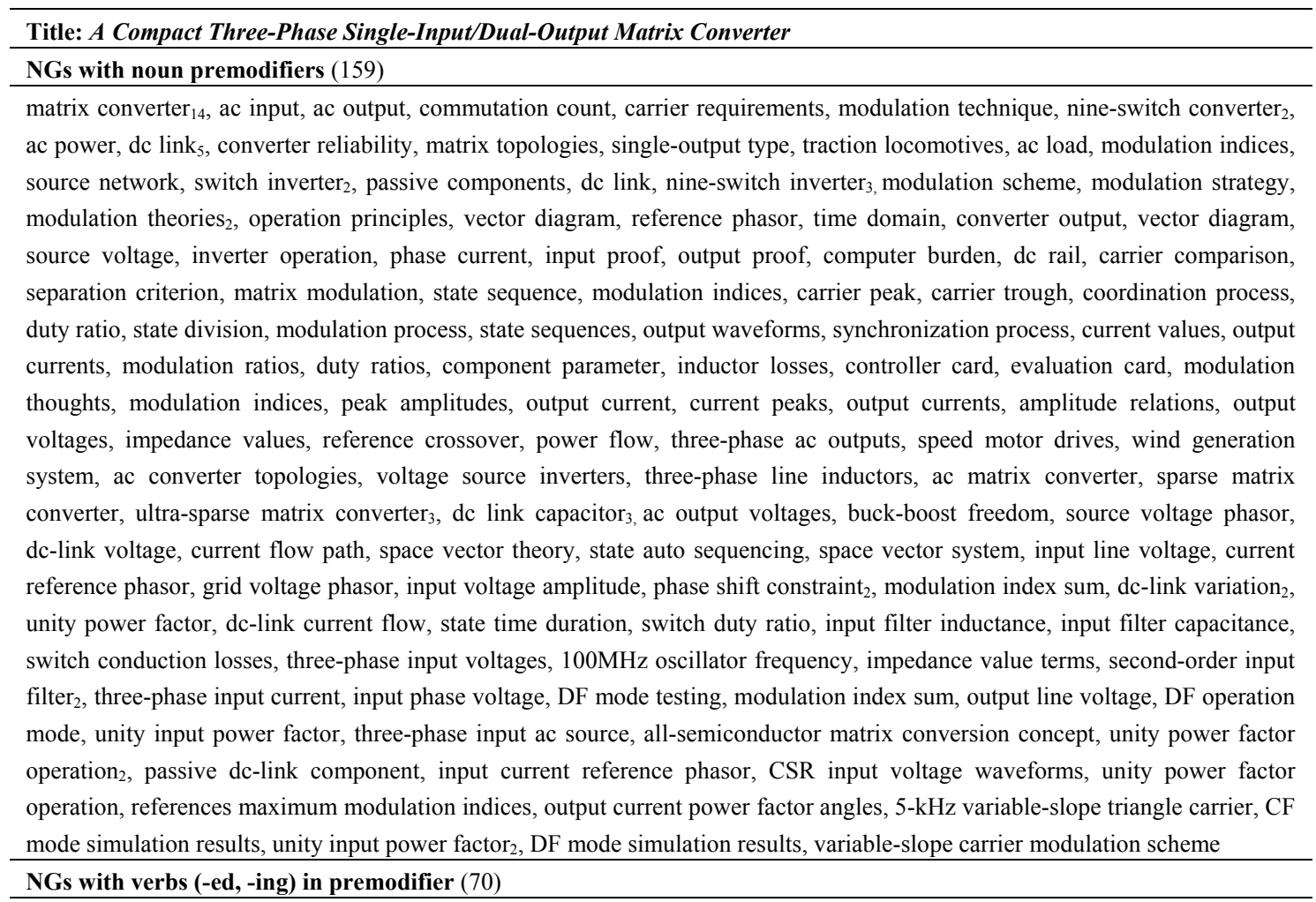
presented topology, proposed converter, resulting topology, presented concepts, operating modes, cascading basis, modulating conditions, combined effects, switching process, clamped switch, modulated switches, rising slopes, falling slopes, modulating references $_{2}$, falling edge, switching losses, implemented hardware, modulating references, filtered input, carrier based method, carrier based modulation, nine-switch proposed concept, existing nine-switch inverters 2 , presently unsolved shortcomings, hidden concept details, required power flow, operating possible scenarios, proposed matrix converter, assumed remaining voltages, middle shared switches, chosen space vector, carrier based modulation, carrier based approach, imposed line voltage, normalized six-pulse variation, allowed switching states, unwanted switching states, falling edge duration, shown carrier diagrams, resulting state sequences, normalized modulating references, normalized modulating voltages, obtained resulting expressions, input damping resistance, expected regeneration capability, observed input currents, per phase modulating references, proposed single-input/dual-out matrix converter, bulk-rated passive components, resulting proposed matrix converter, associated dc-link 
modulation values, applied dc-link voltage $V_{d c}$, matrix converter carrier based modulation, modulated switch duty ratio, varying dc-link voltage, constrained phase-leg switching states, varying-slope triangle carrier, CSR switching state duration, modified carrier rising edge duration, switched-controlled three-phase terminals, anticipated CSR commutation losses, proposed matrix converter input current, carrier-based modulation scheme, overall matrix converter driving signals, per phase modified modulating references 2 , modulation indices imposed limits

\section{NGs with adverbs in premodifier (21)}

rear-end inverter, top-to-bottom current, rear-end six-switch inverter, back-to-back converter 2 , back-to-back topology, front-end current-source rectifier, presently unsolved shortcomings, rear-end nine-switch voltage ${ }_{2}$, middle shared switches, sizeable lookup table, high-end control verification, same amplitude output voltages, rear-end voltage source inverter, short-term energy storing purposes, higher rated dc-link capacitor, front-end CSR matrix converter, yet-to-be proven remaining feature, top to bottom three-phase output currents, top to bottom filtered input currents

\section{NGs with prepositions in premodifier (9)}

on switches, follow-up attempt, per phase modulating references, per phase-leg three switching states, overall matrix converter driving signals, per phase modified modulating references ${ }_{2}$, in-phase input phase voltage, over a half current voltage cycle

The most frequent grammar feature found in NGs is the 'noun $+X$ noun' premodifier, followed by -ed and -ing verbs, adverbs and adverbial phrases, and, finally, prepositions. Students enjoyed this activity, which reinforced their awareness of NGs presence in scientific language and helped them intake this EST structure. They were encouraged to carry out further tasks on their own, which could be uploaded online together with the work on the ten articles discussed in class.

\subsubsection{Further Related Tasks}

Practice in developing NGs of varying levels of complexity is useful as a basis both for understanding and producing compounds. This we found to be an excellent way of making clear to the students the difference between headword and modifiers. Some of the exercises carried out by our students were:

a) Giving the students lists of technical and subtechnical words from their own field, they were asked to create NGs of two, three and four elements. Then, students were encouraged to write complete sentences defining some of the NGs they had created, as in the examples:

-'metal distribution ratio' is the ratio of the distribution of a metal (along the cathode).

-'lithium battery diffusion coefficients' are the coefficients of diffusion of a lithium battery.

b) Say if the given phrases contain nominal groups by ticking the correct answers (three example items are given):

\section{1 A more efficient system}

2. 1 An emitting gas

\section{1 A light diode}

c) Using scientific real texts written in Spanish, students were asked to translate some paragraphs using NGs structure whenever appropriate.

All these type of tasks were uploaded in the Web classroom platform so that students could access to all the linguistic documentation on the matter. A key to check the answers was provided so that students could evaluate their progress.

\section{Results}

\subsection{Results in Direct Translation}

In order to determine whether there are any significant differences between the means of the independent CERF level groups, and their initial and final test performance according to the complexity of the NG, the analysis of variance (ANOVA) test was used. A $p$-value $\leq 0$ ' 5 was established to accept the significant differences among means. Table 1 shows the validity of results as they are way above the $95 \%$ level of confidence set for the study. 
Table 1. ANOVA results in direct translation pre and post tests

\begin{tabular}{llllll}
\hline Variables & Sum of Squares & Df & Mean square & F-Ratio & P-value \\
\hline A: DIFFICULTY & 30.9364 & 2 & 15.4682 & 14.76 & 0.0000 \\
B: CERF LEVEL & 24.1220 & 3 & 8.0406 & 7.67 & 0.0001 \\
INTERACTION A \& B & 50.1512 & 6 & 8.3585 & 7.98 & 0.0000 \\
\hline
\end{tabular}

Table 2 and Figures 1 and 2 show the NGs direct translation test results of the 50 participants. Their CERF English level and the results obtained taking into account the number of elements that formed the NGs ${ }^{\text {are }}$ shown. They scored over a maximum of ten points.

Table 2. Comparison of mean results between initial and final tests in direct translation

\begin{tabular}{cllll}
\hline NG elements & CEFR level & No. of students & Initial test & Final Test \\
\hline Simple: 2 & A2 & 7 & 6,07 & 8,21 \\
2 & B1 & 21 & $7,^{3} 8$ & 9,28 \\
2 & B2 & 14 & 7,50 & 9,32 \\
2 & C1 & 8 & 10,00 & 10,00 \\
\hline Complex: 3 & A2 & 7 & 2,42 & 6,14 \\
3 & B1 & 21 & 4,95 & 7,61 \\
3 & B2 & 14 & 7,28 & 9,07 \\
3 & C1 & 8 & 8,37 & 9,05 \\
\hline V. complex: 4 & A2 & 7 & 0,98 & 3,72 \\
4 & B1 & 21 & 3,29 & 5,42 \\
4 & B2 & 14 & 5,05 & 8,17 \\
4 & C1 & 8 & 6,25 & 9,50 \\
\hline
\end{tabular}
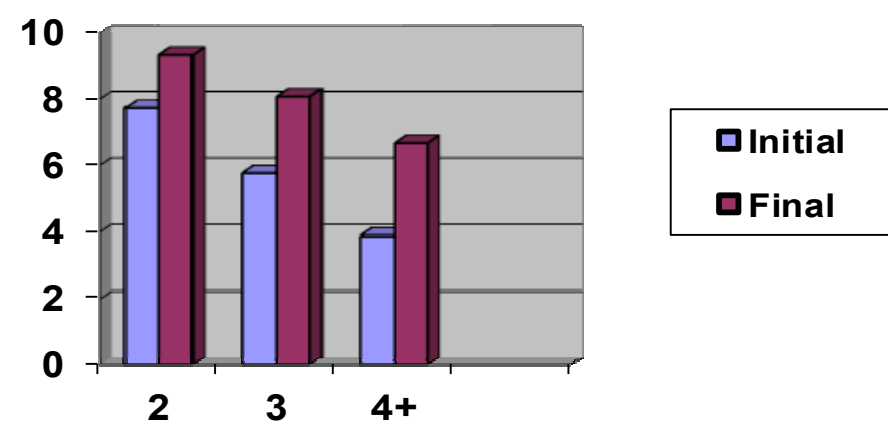

Figure 1. Initial and final means according to no. of NG elements in L2/L1 translation test

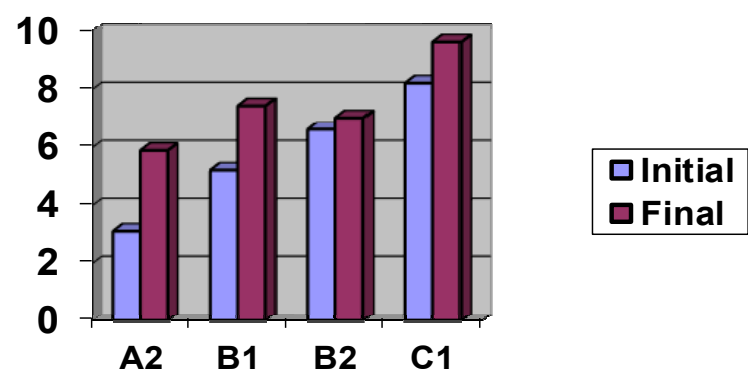

Figure 2. Initial and final means by CERF English level in L2/L1 translation test

\subsection{Results in Inverse Translation}

As in 4.1, to find out whether there are any significant differences between the means of the independent CERF level groups, and their initial and final test performance in inverse translation, taking into account the complexity 
of the NG, the analysis of variance (ANOVA) test was used. A p-value $\leq 0{ }^{\prime} 5$ was established to accept the significant differences among means. Table 1 shows the validity of results as all of them are over a $95 \%$ level of confidence.

Table 3. ANOVA results in inverse translation pre and post tests

\begin{tabular}{llllll}
\hline Variables & Sum of Squares & Df & Mean square & F-Ratio & P-value \\
\hline A: DIFFICULTY & 155.712 & 2 & 77.8562 & 75.65 & 0.0000 \\
B: CERF LEVEL & 6.2725 & 3 & 2.0908 & 2.03 & 0.1123 \\
INTERACTION A \& B & 18.3867 & 6 & 3.0644 & 2.98 & 0.0091 \\
\hline
\end{tabular}

Table 4 and figures 3 and 4 show the mean results of students' inverse translation initial and final tests

Table 4. Comparison of results between initial and final test means in L1/L2 translation

\begin{tabular}{lllll}
\hline NG elements & CEFR level & No. of students & Initial test & Final Test \\
\hline Simple: 2 & A2 & 7 & 3,71 & 5,42 \\
2 & B1 & 21 & 5,90 & 7,90 \\
2 & B2 & 14 & 7,85 & 8,86 \\
2 & C1 & 8 & 8,50 & 10,00 \\
\hline Complex: 3 & A2 & 7 & 3,14 & 5,00 \\
3 & B1 & 21 & 3,55 & 6,02 \\
3 & B2 & 14 & 4,90 & 7,56 \\
3 & C1 & 8 & 6,08 & 8,40 \\
\hline V. complex: 4 & A2 & 7 & 0,61 & 5,31 \\
4 & B1 & 21 & 1,49 & 5,87 \\
4 & B2 & 14 & 3,26 & 7,75 \\
4 & C1 & 8 & 5,17 & 8,43 \\
\hline
\end{tabular}

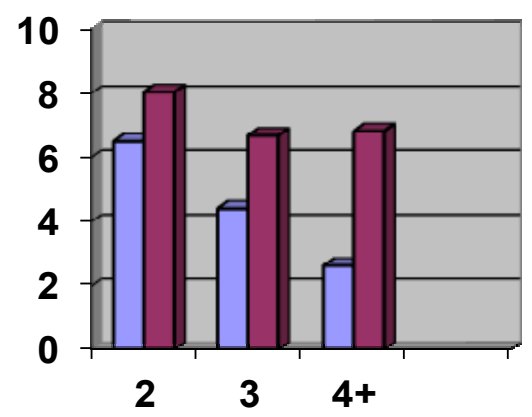

\section{DInitial
DFinal}

Figure 3. Initial and final test means by number of NGs elements in L1/L2 translation

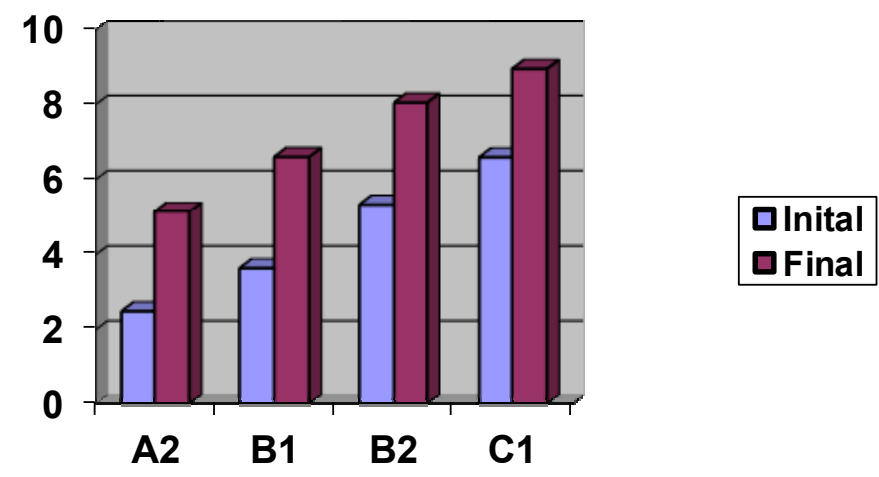

Figure 4. Initial and final test means by CERF English level in L1/L2 translation 


\section{Discussion of Results}

Considering the mean results of the entire group of students who participated in the study we may affirm that the statistical analysis shows a high relationship between the intensive teaching of the NGs linguistic feature studied, and the students' final performance in both direct and inverse translation tests. Therefore, we may say that intake of NGs structure has taken place. Tables 2 and 4 show the detailed improvement in their mean results, noting that the four subgroups (A2, B1, B2 and C1) experienced an improvement both in direct and indirect translation, except in the case of $\mathrm{C} 1$ simple ( 2 elements) NGs whose initial mark reached the maximum 10 points.

However, regarding the two variables studied, student CERF English level and the number of NGs elements, we find several differences worth discussing:

a) A2 level students do not seem to have the linguistic background required to face the acquisition of a linguistic structure inexistent in their L1, hence their low results (below 60\%) in complex NGs translation, except for simple (two element) NGs. In direct translation, their final means in simple, complex, and very complex NGs are 8.21, 6.14 and 3.72, respectively. In Spanish to English translation, their means in the final test are much lower, $5.42,5.00$ and 5.31. Given the high intellectual capacity of these students, they can assimilate syntactic rules by practising tasks focused on NGs linguistic feature, as can be seen in figures 2 and 4 showing their improvement in both tests. We may affirm that Spanish A2 engineering students learning English can accelerate their progress in NGs acquisition, but they will not probably acquire this language feature until their general language level has not improved (Note 4).

b) Independent B1 level students identify and use NGs obtaining means above 6 in simple and complex direct and inverse translation. However, in very complex NGs marks they do not reach $60 \%$ correct answers, being their final grades 5.42 and 5.87, in direct and inverse translation tests respectively.

c) Independent B2 students obtain very good punctuation-above 8 marks-in direct translation and above 7.5 marks in inverse translation. We may say that they are capable of intaking NG use in English and will most probably use it competently when writing their scientific reports and articles.

d) Competent $\mathrm{C} 1$ users understand and use simple and complex NGs successfully after instruction. Their average scores in Spanish to English translation (10,8.4 and 8.43) are just a bit lower than the direct translation scores $(10,9.05$ and 9.5). $\mathrm{C} 1$ language users have shown improvement in their initial and final marks (figures 2 and 4) and they seem to handle this EST structure competently.

As a whole, complex and very complex NGs ( 3 and $4+$ elements) were the ones that presented more difficulty to all students, as could be expected, but students test performance of initial and final tests showed that, after noticing activities, these two NGs were the ones that showed a greater improvement, as it is depicted in figures 1 and 3 .

\section{Conclusion}

The results' statistical analysis revealed that, through this technology-enhanced English learning, the entire group improved their ability to use noun compounds correctly, and that the students' CEFRL language level influenced the student's initial and final marks, but not their improvement in noun compound use, which was highly satisfactory in all cases. It was shown that this approach, which integrated technology into the course methodology, improved the students' performance and, therefore, it can be profitably exploited for the acquisition of grammar competence. In conclusion, explicit grammar knowledge can foster the acquisition of implicit knowledge through noticing and intake of 'learnable' new language structures; i.e., teachers can draw students' attention to certain language features of input through explicit instruction. By increasing the frequency and perceptual salience of the structure, and/or designing tasks that require the students to notice the structure, learners will acquire it or, at least, move one step forward in language proficiency to increase their readiness for its intake.

On the other hand, for a language multilevel group, as it was the case, the opportunity for sharing work and exchanging answers to different tasks is considered to be a good learning experience. Furthermore, the teacher's possibility to get in touch with individual students or with a group, via e-mail, has proven to be highly satisfactory. The technology used has helped students to train themselves and practice the identification and use of NGs in scientific writing. The Web classroom has also been of great help to professors to evaluate students and to offer guidance in their intake process of this difficult grammar structure. 


\section{References}

Biber, D., Conrad, S., \& Reppen, R. (1998). Corpus Linguistics: Investigating Language Structure and Use (Cambridge Approaches to Linguistics). Cambridge: Cambridge University Press. http://dx.doi.org/10.1017/CBO9780511804489

Bocanegra, A. (2007). On the teachability of nominal compounds to Spanish learners of English for specific purposes. In English for Specific Purposes: Studies for Classroom Development and Implementation (pp. 73-93). Cádiz: UCA Servicio de publicaciones.

Corder, S. P. (1967). The significance of learners' errors. IRAL, 5, 161-170. http://dx.doi.org/10.1515/iral.1967.5.1-4.161

Council of Europe. (2001). Common European Framework of Reference for Languages: Learning, teaching, assessment. Cambridge: Cambridge University Press.

Cross, J. (2002). 'Noticing' in SLA: Is it a Valid Concept? TESL-EJ., 6(3). Retrieved from http://www-writing.berkeley.edu/TESL-EJ/ej23/a2.html

Durán, P., \& Rubio, A. L. (2015). Evaluación del uso competente de los rasgos lingüísticos del IPA en relación con los niveles del MCER. Revista de Lingüistica y Lenguas Aplicadas, 10 (in press).

Ellis, R. (1990). Instructed Second Language Acquisition. Oxford: Basil Blackwell.

Ellis, R. (2002). The Place of Grammar Instruction in the Second/Foreign Language Curriculum. In S. Fotos \& E. Hinkel (Eds.), New Perspectives on Grammar Teaching in Second Language Classrooms (pp. 17-34). Mahwah, NJ: Lawrence Erlbaum Associates, Inc.

Girju, R., Moldovan, D., Tatu, M., \& Antohe, D. (2005). On the semantics of noun compounds. Computer Speech and Language, 19, 479-496. http://dx.doi.org/10.1016/j.csl.2005.02.006

Halliday, M., \& Martin, J. (1993). Writing Science: Literacy and discourse power. London: Falmer Press.

Long, M. H. (1988). Instructed interlanguage development. In L. Beebe (Ed.), Issues in second language acquisition: Multiple perspectives (pp. 115-141). New York: Newbury House.

Newmark, P. (1992). A textbook of translation. London: Prentice Hall.

Pienemann, M., \& Johnston, M. (1987). Factors Influencing the Development of Language Proficiency. In D. Nunan (Ed.), Applying Second Language Acquisition Research. Adelaide: National Curriculum Resource Centre, Adult Migrant Education Program.

Rubio, A. L. (2015). La competencia lingüistica en el uso de los grupos nominales en inglés académico y profesional y su didáctica: estudio empírico (Unpublished Doctoral Dissertation). Universidad Politécnica de Madrid: Madrid.

Salager-Meyer, F. (1984). Compound nominal phrases in Technical Literature: Proportion and Rationale. In A. K. Pugh \& J. M. Ulijn (Eds.), Reading for Professional Purposes. London: Heinemann.

Schmidt, R. (1990). The role of consciousness in second language learning. Applied Linguistics, 11, 129-158. http://dx.doi.org/10.1093/applin/11.2.129

Schmidt, R. (1995). Consciousness and foreign language learning: A tutorial on the role of attention and awareness. In R. Schmidt (Ed.), Attention and awareness in foreign language teaching and learning (Technical Report No. 9) (pp. 1-64). Honolulu: University of Hawai'i at Manoa.

Skehan, P. (1998). A cognitive approach to language learning. Oxford: Oxford University Press.

Soto, G., Martínez, R., \& Sadowsky, S. (2006). Verbos y sustantivos en textos científicos. Análisis de variación en un corpus de textos de ciencias aplicadas, naturales, sociales, y humanidades. Retrieved from http://sadowsky.cl/files/verbos

Spada, N., \& Lightbow, P. M. (1999). Instruction, First Language Influence and Developmental Readiness in L2 Acquisition. The Modern Language Journal, 83(1), 1-22. http://dx.doi.org/10.1111/0026-7902.00002

Titford, C. (1983). Translation for advanced learners. ELT Journal, 37(1), 52-57. $\mathrm{http}: / / \mathrm{dx}$. doi.org/10.1093/elt/37.1.52

Trimble, L. (1985). English for Science and Technology: A Discourse Approach. Cambridge: Cambridge University Press. 
Van Patten, B. (2002). Processing instruction: An update. Language Learning, 52, 755-803. http://dx.doi.org/10.1111/1467-9922.00203

\section{Notes}

Note 1. Common European Framework of Reference (CERF) language competence levels are established this way: A1, A2 [Basic User]; B1, B2 [Independent User]; and C1, C2 [Competent User].

Note 2. The Oxford Placement Test (OPT) is an automatically marked test, which gives accurate, reliable and instant results, so you can find out students language level. Results are calibrated to the CEFR language levels. The test was taken online in the Web classroom. They were allowed 35 mins to complete the 'use of language' written section; the listening comprehension section was left out for this study.

Note 3. IEEE stands for Institute of Electrical and Electronics Engineers

Note 4. In his Input Hypothesis, Krashen defines 'comprehensible input' as L2 input just beyond the learner's current L2 competence (i+1), in terms of its syntactic complexity.

\section{Copyrights}

Copyright for this article is retained by the author(s), with first publication rights granted to the journal.

This is an open-access article distributed under the terms and conditions of the Creative Commons Attribution license (http://creativecommons.org/licenses/by/3.0/). 